\title{
Assessment of Lung Cytological Atypia among Shisha Smokers
}

\author{
Ali Yousif Yahia Babiker, ${ }^{1}$ Isra Mohammed Khair Abas, ${ }^{2}$ \\ Mohammad A. Alzohairy, ${ }^{1}$ and Hussain Ahmed $^{3}$ \\ ${ }^{1}$ Department of Medical Laboratories (Histopathology and Cytology), College of Applied Medical Sciences, \\ Qassim University, P.O. Box 6699, Buraydah 51452, Saudi Arabia \\ ${ }^{2}$ Department of Histopathology and Cytology, College of Medical Laboratory, \\ University of Sudan for Sciences and Technology, Khartoum 102, Sudan \\ ${ }^{3}$ Department of Pathology, College of Medicine, University of Hail, Hail 2440, Saudi Arabia
}

Correspondence should be addressed to Ali Yousif Yahia Babiker, alibabkr99@gmail.com

Received 16 July 2012; Accepted 31 July 2012

Academic Editors: A.-J. Kruse and C.-F. Li

Copyright ( 2012 Ali Yousif Yahia Babiker et al. This is an open access article distributed under the Creative Commons Attribution License, which permits unrestricted use, distribution, and reproduction in any medium, provided the original work is properly cited.

\begin{abstract}
Objectives. The aim of this study was to assess frequency of lung epithelial atypia among Shisha users. Methods. Sputum samples were collected from 200 subjects ( 100 Shisha users (cases) and 100 nontobacco users (controls)). Cytological smears were prepared and demonstrated using Papanicolaou and silver nucleolar organizer region (AgNORs) methods. Results. Cytological atypia was identified among 2/100 (2\%) of the cases, and no cytological atypia was found among controls. Respiratory squamous metaplasia was significantly higher among cases $42 / 100(42 \%)$, compared to controls $7 / 100(7 \%)(P<0.001)$. Shisha users were found more susceptible for bacterial infections 34 (34\%) compared to controls $3 / 100(3 \%),(P<0.0001)$. The mean AgNOR dots count was higher among cases $(2.3 \pm .23)$ than among controls $(1 \pm .2), P<0.001$. Conclusion. In view of these findings, the consumption of Shisha is a risk factor for cellular proliferation activity in respiratory epithelium. The mean AgNORs count is a useful indicator for prediction of the risk of exposure to certain carcinogenic elements that may induce lung cancer.
\end{abstract}

\section{Introduction}

Lung cancer is a global public health problem. Lung cancer is the leading cause of death worldwide. It accounts for $18 \%$ of all deaths and more than one million deaths a year since 1993 [1]. Earlier detection and followup of cellular atypia are important to predict their malignant potential [2]. The prevalence of potentially malignant oral mucosal lesions shows wide variations between developed and developing countries [2]. The primary risk factors for development of both OSCCs and potentially malignant lesions are considered to be similar $[2,3]$. However, the social habits of "Shisha use" and "Goza" smoking have adverse effects on general health and may predispose to oral cancer [4]. In Sudan, the high prevalence of Shisha use might contribute to development of lung cancer and a variety of oral mucosal changes. Therefore, the objective of the present study was to assess the cellular proliferation activity of lung epithelial atypia among Sudanese Shisha smokers.

\section{Materials and Methods}

In this case control study, 200 volunteers from the city of Khartoum were randomly selected. Of the 200 study subjects, 100 were Shisha users (ascertained as cases) and 100 were nontobacco users (ascertained as controls). All cases and controls were apparently healthy individuals, their ages ranging from 18 to 72 years with a mean age of 29.5 years. Sputum specimens were collected from each individual, in sterile container. Tobacco smokers and alcohol users were excluded both from cases and controls. Personal information and other demographical factors were obtained using purposeful structured questionnaire.

\section{Sample Processing}

Sputum samples were collected by deep cough, and the materials were initially placed in a betri dish, and then the colored area was selected to make the smear. The smears were 
placed in Saccomanno's fixative. The smears were further treated according to Papanicolaou's method [5]. Smears fixed in ethanol were then hydrated in descending ethanol concentrations of $95 \%$ through $70 \%$ to distilled water, for 2 min each. For nuclear staining, smears were treated with Harris's haematoxylin for $5 \mathrm{~min}$, rinsed in distilled water, and differentiated in $0.5 \%$ aqueous hydrochloric acid for $10 \mathrm{sec}$ to remove excess stain particles and then immediately rinsed in distilled water to stop decolouration. Thereafter, smears were stained blue in alkaline water for $4 \mathrm{sec}$ and dehydrated in ascending ethanol concentrations of $70 \%$ through two changes of $95 \%$, for 2 min each. For the cytoplasmic staining, smears were treated with Papanicolaou Orange G6 solution for $2 \mathrm{~min}$, rinsed in 95\% ethanol, and treated in Papanicolaou EA50 staining solution for $3 \mathrm{~min}$. Finally, the smears were dehydrated in $95 \%$ through absolute ethanol, cleared in xylene, and then mounted in the DPX (distrene polystyrene xylene) mount. Other smears were stained using silver nitrate method for AgNOR protein sites. Fifty percent silver nitrate and $2 \%$ gelatin in $1 \%$ formic acid were the components. Smears were hydrated in $70 \%$ alcohol for $2 \mathrm{~min}$, rinsed in distilled water, and then incubated in freshly prepared working solution $(2: 1)$. For $45 \%$ at dark and moist area, they were then washed by distilled water and $5 \%$ sodium thiosulphate, dehydrated in two changes of absolute alcohol, cleared in two changes of Xylene, and mounted with DPX medium.

3.1. Cytological Assessment of the Epithelial Atypia. In brief, The presence of two or more of the following features was consistent with atypia: nuclear enlargement, associated with the increased nuclear/cytoplasmic ratio, nuclear hyperchromatism, chromatin clumping with prominent nucleation, irregularity of nuclear membranes, bi- or multinucleation, and increased keratinization [6]. Five sputum smears obtained from patients known with cytological atypia were included to serve as internal controls.

3.2. Ethical Consent. Each participant was asked to sign a written ethical consent during the interview, before the specimen was taken. The informed ethical consent form was designed and passed by the ethical committee of Faculty Research Board, FMLS, Sudan University for Science and Technology.

3.3. Data Analysis. Statistical Package for Social Sciences (version 12) was used for analysis and to perform Pearson chi-square test for statistical significance ( $P$ value). The $95 \%$ confidence level and confidence intervals were used.

\section{Results}

The male-female ratio was $1.0: 1.0$. The age distribution are similar among the cases and the controls. The mean age of the study population was 29.5 years with a range of 18 to 70 years. Cytological atypia was identified among 2/100 (2\%) of the cases, and no cytological atypia was found among controls. Respiratory squamous metaplasia was significantly
TABLE 1: Distribution of the study population by age and metaplasia.

\begin{tabular}{lccc}
\hline \multirow{2}{*}{ Age group } & \multicolumn{2}{c}{ Metaplasia } & Total \\
& Presence & Absence & \\
\hline$<20$ years & 7 & 20 & 27 \\
$21-25$ & 8 & 36 & 44 \\
$26-30$ & 11 & 55 & 66 \\
$31-35$ & 10 & 23 & 33 \\
$36+$ & 13 & 17 & 30 \\
\hline Total & 49 & 151 & 200 \\
\hline
\end{tabular}

TABle 2: Description of the study population by cytological findings.

\begin{tabular}{lccc}
\hline Variable & Cases & Controls & $P$ value \\
\hline Atypia & & & \\
$\quad$ Positive & 2 & 0 & 0.001 \\
$\quad$ Negative & 98 & 100 & \\
Metaplasia & & & \\
$\quad$ Positive & 42 & 7 & 0.001 \\
$\quad$ Negative & 58 & 93 & \\
Fungal infection & & & \\
$\quad$ Positive & 7 & 2 & 0.001 \\
$\quad$ Negative & 93 & 98 & \\
Bacterial infection & & & \\
$\quad$ Positive & 34 & 3 & 0.0001 \\
$\quad$ Negative & 66 & 97 & \\
Mean NOR counts & & & \\
$\quad<2$ & 84 & 100 & 0.001 \\
$\quad 2.1+$ & 16 & 0 & \\
\hline
\end{tabular}

higher among cases $42 / 100$ (42\%), compared to controls $7 / 100(7 \%)(P<0.001)$. The mean AgNOR dots count was higher among cases $(2.3 \pm .23)$ than among controls $(1 \pm .2)$, $P<0.001$. According to mean NORs, a mean of $<2$ dots and 2.1 dots was counted in 84 and 16 for the cases and 100 and 0 for controls, respectively, $P<0,001$, as indicated in Figure 1 .

In regard to gender, metaplasia was identified among 33 of the males and 16 of the females, $P<0.001$. Furthermore, none of the females showed mean AgNORs count more than two; hence, 16 of the males have showed mean AgNORs count more than two.

Metaplasia was found to increase with the increasing of age, and this was found to be statistically significant, $P<$ 0.04, as indicated in Table 1 .

Acute inflammatory cells infiltrates were identified among 43 and 3 of the cases and controls, respectively. Chronic inflammatory cells infiltrates were demonstrated in 23 and 3 of the cases and controls, respectively, $P<0.0001$. Shisha users were found more susceptible for bacterial infections 34/100 (34\%) compared to controls 3/100 (3\%), $(P<0.0001)$, as indicated in Figure 2. Fungal infection was identified in 7 and 2 of the cases and controls, respectively, $P<0.001$, as indicated in Table 2. 


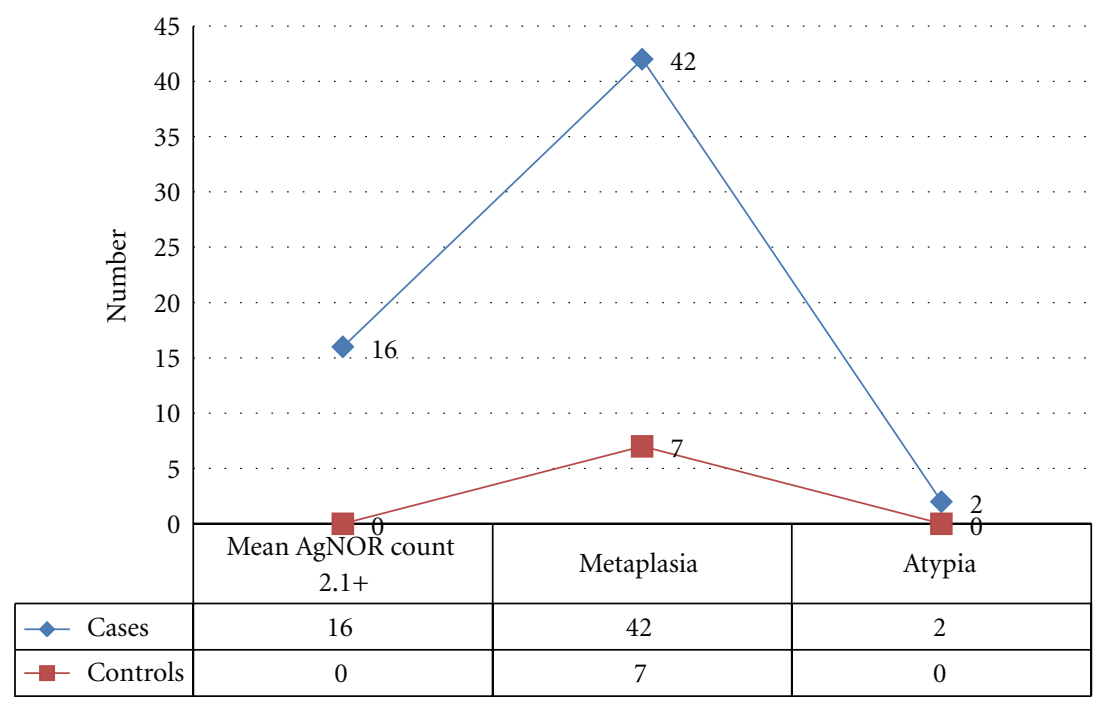

FIGURE 1: Description of cases by cytological atypia and metaplasia.

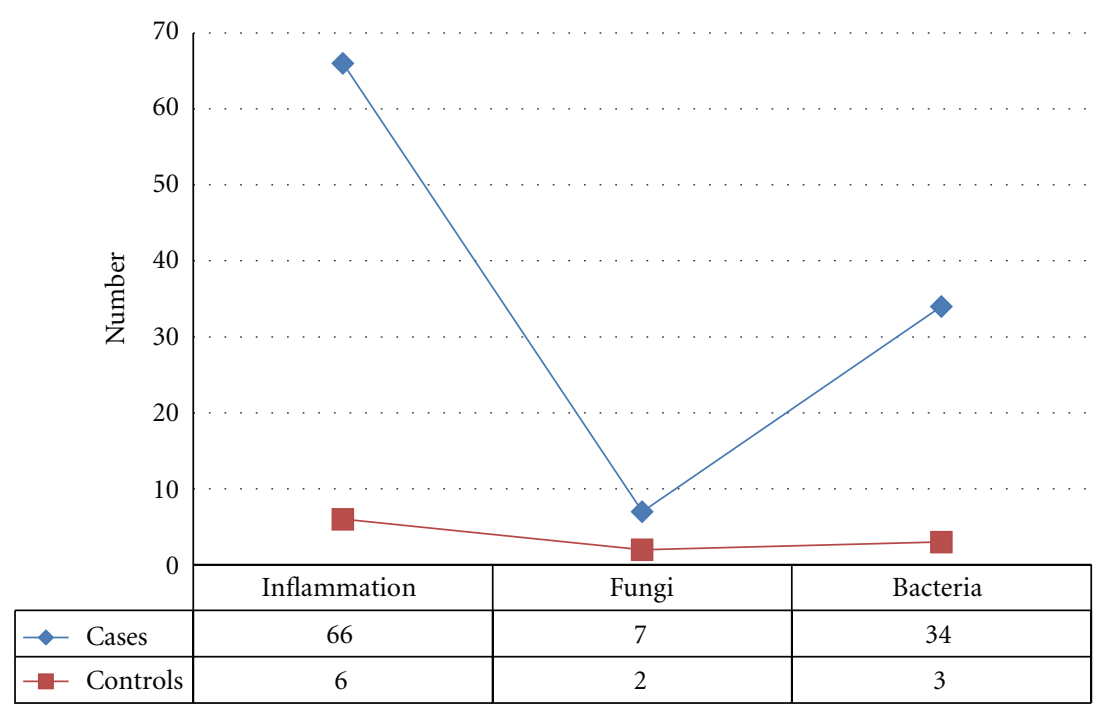

FIGURE 2: Description of cases and controls by bacterial and fungal infections and inflammatory infiltrates.

\section{Discussion}

For the early detection of lung cancer and precancerous lesions in high-risk areas with limited resources, as in the case of Sudan, simple, reliable, and cost-effective screening programs are highly recommended. In this study, the presence of epithelial atypia was quantified by cytology in smears obtained from Shisha users and nontobacco users. To the best of our knowledge, this is the first paper from Sudan to use cytological methods for analysis of lung epithelial atypia in sputum obtained from Shisha users.

In this study, the significant presence of cytological atypia and metaplasia among Shish smokers compared to controls is strong evidence for the role of Shish smoking as a cause of lung epithelial proliferative activity, which may develop to lung precancerous or cancerous lesions. The use of Shisha was previously reported to induce cytological atypia and premalignant changes of lung [7].

In regard to metaplasia, cases were more susceptible than controls, and this was found to be statistically highly significant $(P<0.0001)$. The squamous metaplasia is considered reactive and reversible changes, most frequently associated with the development of squamous cell lung carcinomas [8]. It is clear that tobacco use leads to squamous metaplasia of the airways epithelium, predisposing the tissue to potential malignant transformations [9]. Similar results are also observed in other studies [10]. This means that consecutive annual sputum examination increases the chance of detection of sputum atypia and thus increases the chance of detection of lung cancer.

The case group has significantly higher AgNOR mean count than control group $( \pm 2.1)$, and this indicates that 
Shisha use increases cellular proliferative activity. These findings support the studies by $[11,12]$; they found significant differences in the mean numbers of AgNORs per nucleus between smokers and nonsmokers. Other studies found that the mean AgNOR count was statistically higher in cells of smokers than nonsmokers $(P<0.01)[13,14]$. Furthermore, mean nuclear area of the smoker group is significantly higher than the nontobacco users, which is a similar finding to another study reported elsewhere [15].

In regard to the infection and inflammatory conditions, cases were more susceptible than controls, and this was found to be statistically highly significant $(P<0.0001)$. The nicotine and exposure of respiratory tract epithelium to the Shisha irritating substances (heavy metals such as arsenic, cobalt, chromium, and lead) and carbon monoxide (CO) are major causative factors. Smoking was associated with a 35- to 50 percent increase in the risk of respiratory tract infections and inflammation [16]. These findings are in agreement with other studies suggesting that use of tobacco disturbs the normal maturation of the epithelial cells $[17,18]$.

Males were found more susceptible for overall cellular proliferative activity than females, and this might be attributed to the fact that tobacco use is considered as social stigma among females [19]. Therefore, the frequency of tobacco use among females is lower than males, which might lead to lower risk among females. Furthermore, cytological changes were found to increase with age, which might be due to prolonged exposure of high susceptibility of older people to develop cytological deterioration in the presence of pathogenesis. However, the increase of cytological atypia among older people due to tobacco exposure was previously reported by a study from Sudan [20].

In conclusion, Shisha smoking induces cellular proliferative activity leading to an increased risk of lung cancer. Sputum cytology might be helpful to identify highrisk individuals who could benefit from more intensive diagnostic examination and/or be enrolled into lung cancer chemoprevention trials.

\section{References}

[1] A. J. Alberg, J. G. Ford, and J. M. Samet, "Epidemiology of lung cancer: ACCP evidence-based clinical practice guidelines," Chest, vol. 132, no. 3, supplement, pp. 29S-55S, 2007.

[2] N. W. Johnson, A. W. Ranasinghe, and K. A. Warnakulasuriya, "Potentially malignant lesions and conditions of the mouth and oropharynx: natural history cellular and molecular markers of risk," European Journal of Cancer Prevention, vol. 2, supplement 2, pp. 31-51, 1993.

[3] S. Franceschi, E. Bidoli, R. Herrero, and N. Muñoz, "Comparison of cancers of the oral cavity and pharynx worldwide: etiological clues," Oral Oncology, vol. 36, no. 1, pp. 106-115, 2000.

[4] I. E. El-Hakim and M. A. E. Uthman, "Squamous cell carcinoma and keratoacanthoma of the lower lip associated with "Goza" and "Shisha" smoking," International Journal of Dermatology, vol. 38, no. 2, pp. 108-110, 1999.

[5] J. D. Bancroft, A. Steven, and D. Turner, Theory and Practice of Histological Tchninques, Churchill Livingstone, 4th edition, 1996.
[6] H. G. Ahmed and D. Ai Elemirri, "Assessment of oral cytological changes associated with exposure to chemotherapy and/or radiotherapy," Cyto Journal, vol. 6, article 8, 2009.

[7] J. Rakower and B. Fatal, "Study of narghile smoking in relation to cancer of the lung," British Journal of Cancer, vol. 16, pp. 16, 1962.

[8] S. Lam, J. C. LeRiche, Y. Zheng et al., "Sex-related differences in bronchial epithelial changes associated with tobacco smoking," Journal of the National Cancer Institute, vol. 91, no. 8, pp. 691-696, 1999.

[9] J. P. Hanrahan, I. B. Tager, M. R. Segal et al., "The effect of maternal smoking during pregnancy on early infant lung function," American Review of Respiratory Disease, vol. 145, no. 5, pp. 1129-1135, 1992.

[10] F. B. J. M. Thunnissen, "Sputum examination for early detection of lung cancer," Journal of Clinical Pathology, vol. 56, no. 11, pp. 805-810, 2003.

[11] T. B. Einstein and B. Sivapathasundharam, "Cytomorphometric analysis of the buccal mucosa of tobacco users," Indian Journal of Dental Research, vol. 16, no. 2, pp. 42-46, 2005.

[12] G. H. Blake, T. D. Abell, and W. G. Stanley, "Cigarette smoking and upper respiratory infection among recruits in basic combat training," Annals of Internal Medicine, vol. 109, no. 3, pp. 198-202, 1988.

[13] P. Sethi and P. M. Shah, "Oral exfoliative cytology of smokers at discrete clinical stages using AgNOR staining," Indian Journal of Dental Research, vol. 14, no. 3, pp. 142-145, 2003.

[14] P. C. Fontes, G. H. Corrêa, J. S. Issa, A. A. Brandão, and J. D. Almeida, "Comparison of exfoliative pap stain and AgNOR counts of the tongue in smokers and nonsmokers," Head and Neck Pathology, vol. 2, no. 3, pp. 157-162, 2008.

[15] C. Hde Sampaio, A. M. Loyola, R. S. Gomez, and R. A. Mesquita, "AgNOR count in exfoliative cytology of normal buccal mucosa: effect of smoking," Acta Cytologica, vol. 43, no. 2, pp. 117-120, 1999.

[16] A. I. Orellana Bustos, I. L. Espinoza Santander, M. E. Franco Martínez, N. Lobos Jaimes-Freyre, and A. V. Ortega Pinto, "Evaluation of keratinization and AgNORs count in exfoliative cytology of normal oral mucosa from smokers and nonsmokers," Medicina Oral, vol. 9, no. 3, pp. 197-203, 2004.

[17] S. Babu, R. V. Bhat, P. U. Kumar et al., "A comparative clinicopathological study of oral submucos fibrosis in habitual chewers of pan masala and betel quid," Journal of Toxicology, vol. 34, no. 3, pp. 317-322, 1996.

[18] G. M. Ortiz, A. M. Pierce, and D. F. Wilson, "Palatal changes associated with reverse smoking in Filipino women," Oral Diseases, vol. 2, no. 3, pp. 232-237, 1996.

[19] H. G. Ahmed and R. M. Mahgoob, "Impact of Toombak dipping in the etiology of oral cancer: gender-exclusive hazard in the Sudan," Journal of Cancer Research and Therapeutics, vol. 3, no. 2, pp. 127-130, 2007.

[20] H. G. Ahmed, A. M. Idris, and S. O. Ibrahim, "Study of oral epithelial atypia among sudanese tobacco users by exfoliative cytology," Anticancer Research, vol. 23, no. 2, pp. 1943-1949, 2003. 


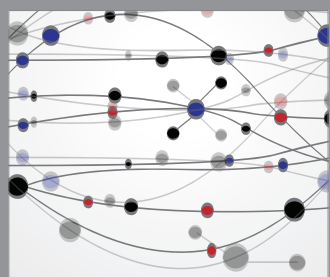

The Scientific World Journal
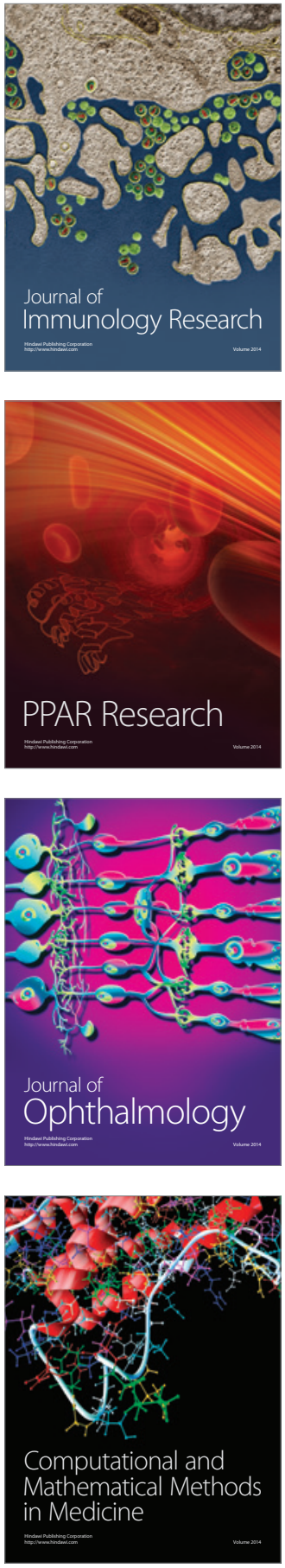

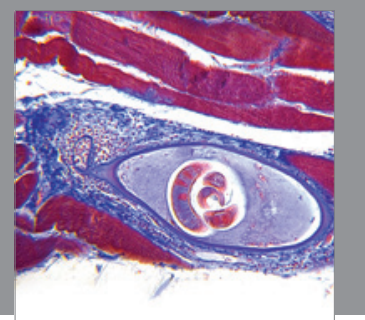

Gastroenterology

Research and Practice
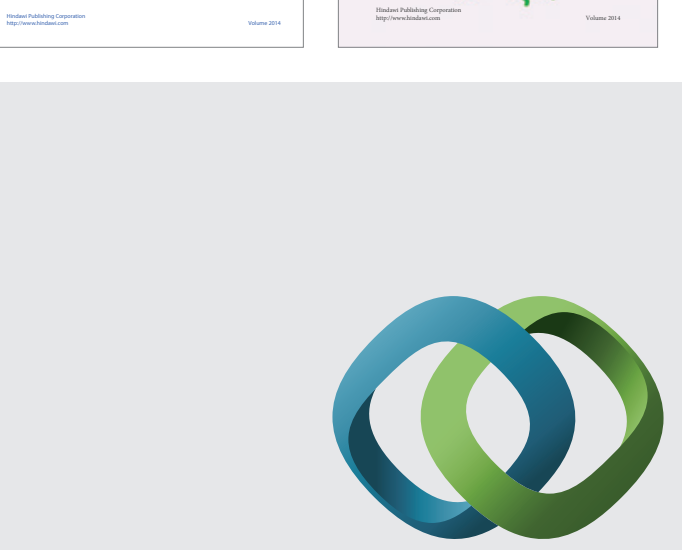

\section{Hindawi}

Submit your manuscripts at

http://www.hindawi.com
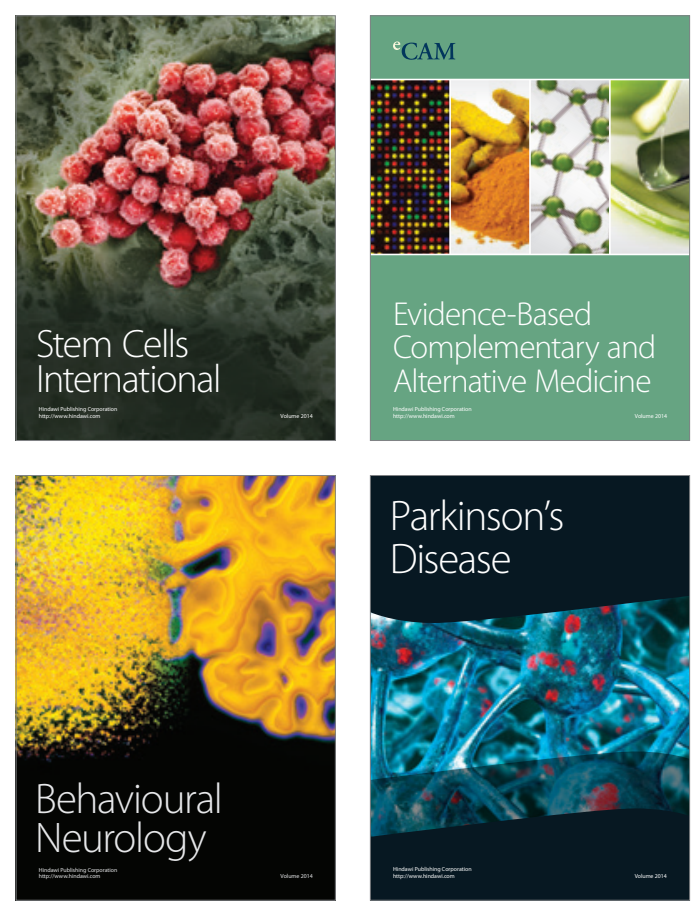

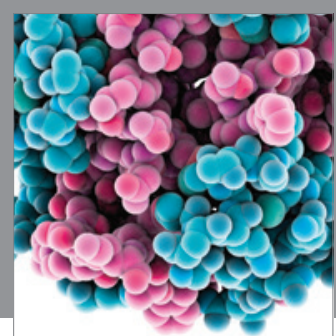

Journal of
Diabetes Research

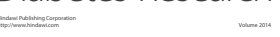

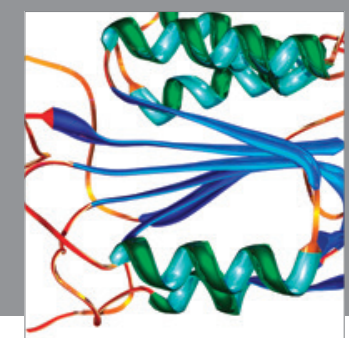

Disease Markers
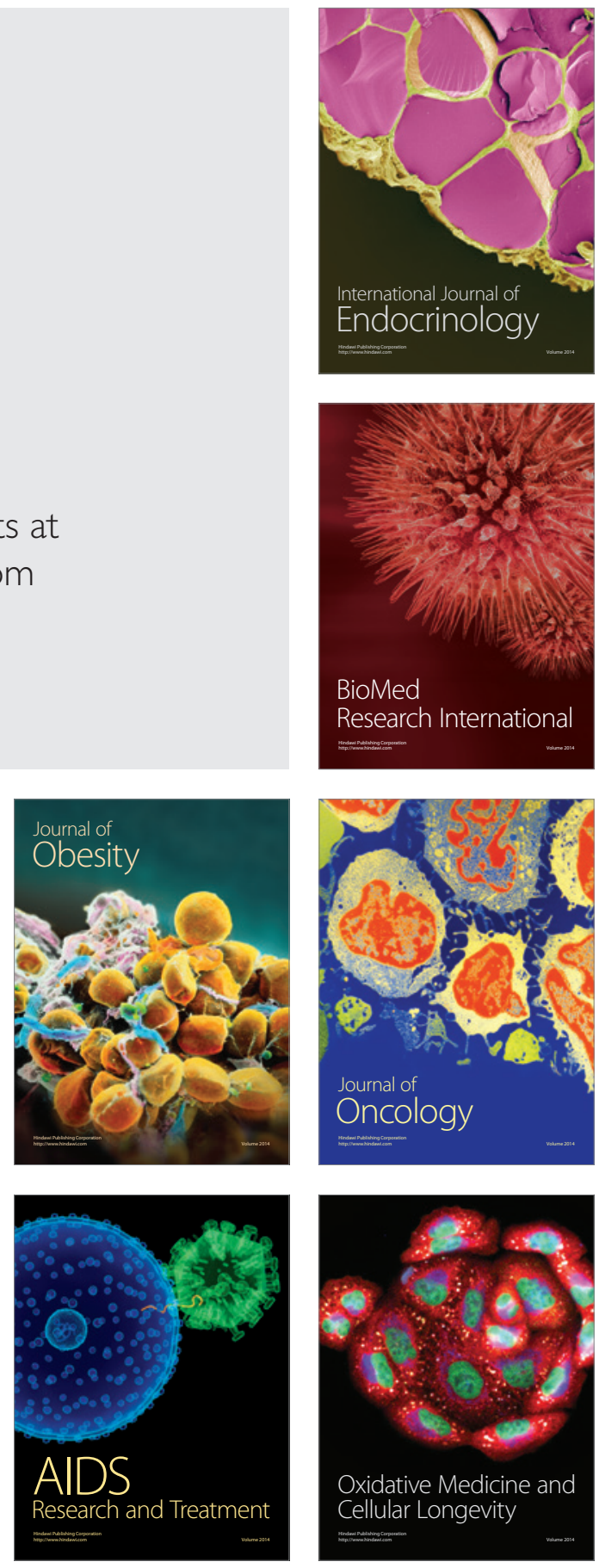